\title{
Esophagitis dissecans: a rare cause of odynophagia
}

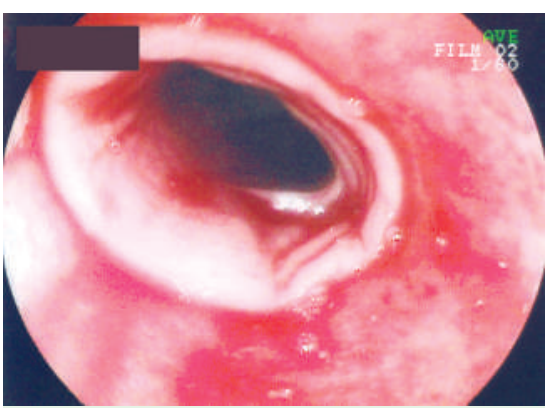

Figure 1 Endoscopic view of the esophagus, showing stripping of the mucosa and white slough.

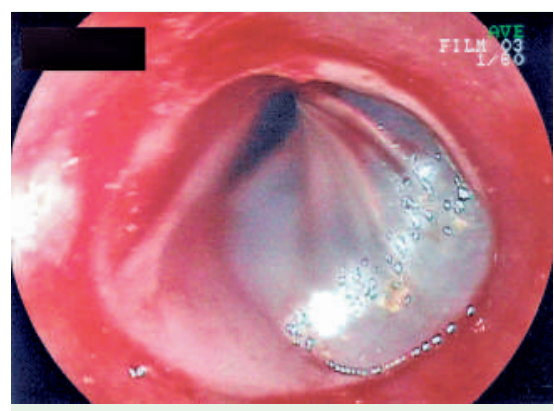

Figure 2 Endoscopic view of the esophagus, showing a bulla.

A 67-year-old woman with Sjögren's syndrome, IgA paraproteinemia, and bronchiectasis presented with a 3-month history of worsening odynophagia and weight loss. Initial endoscopy revealed erythema in the mid- to distal esophagus and a small mucosal tear. Barium swallow, esophageal manometry, and 24-hour $\mathrm{pH}$ studies were all normal. Her symptoms worsened despite proton-pump inhibitor therapy. Repeat endoscopy showed denuded mucosa with overlying slough in the mid-esophagus ( $\bullet$ Figure 1 ) and a superficial bulla ( $\bullet$ Figure 2 ). The patient had no mucocutaneous lesions and an empirical trial of oral corticosteroids was ineffective. Esophageal biopsies showed ulcerated and inflamed squamous mucosa ( 0 Figure 3), but indirect immunofluorescence studies were negative. Fungal hyphae were noted but antifungal therapy was unsuccessful. All routine and autoimmune-screen blood tests were essentially normal. She later developed generalized lymphadenopathy and diffuse large B-cell lymphoma was diagnosed. Treatment with rituximab (anti-CD 20) resulted in a rapid improvement in her dysphagia, and

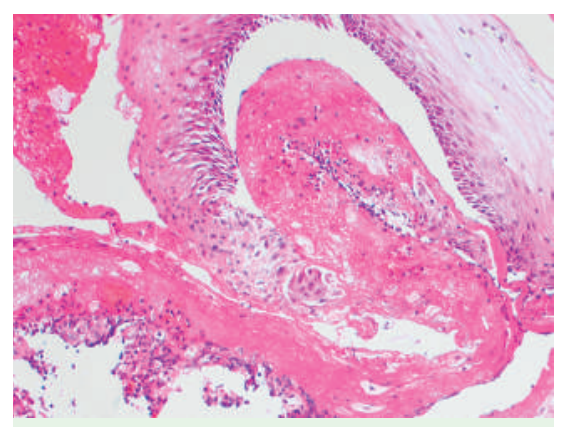

Figure 3 Histological view showing strips of viable tissue within necrotic squamous epithelium (hematoxylin and eosin stain, original magnification $\times 100$ ).

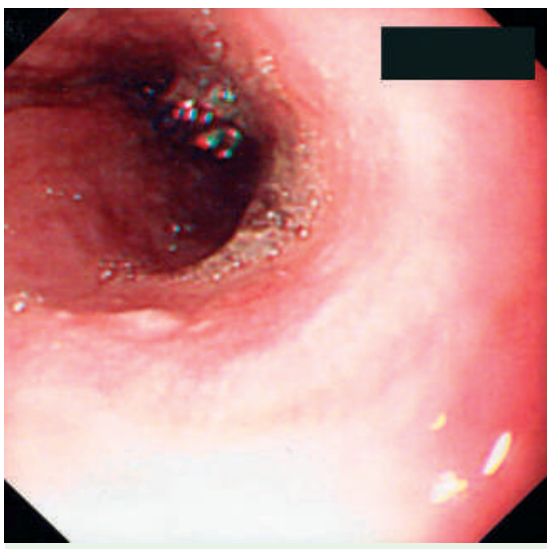

Figure 4 Endoscopic view of the esophagus after treatment with rituximab.

subsequent endoscopy showed normal mucosa with a fibrotic esophageal stricture, which was dilated ( $\bullet$ Figure 4 ). Biopsies showed only mild, nonspecific inflammation and no malignancy.

Spontaneous bullous esophagitis is rare and is usually associated with cutaneous diseases, including the bullous dermatoses (pemphigus, pemphigoid), lichen planus, and Stevens-Johnson syndrome. Chronic esophagitis dissecans was first described by Ponsot et al. [1] and is characterized by recurrent dysphagia, due to spontaneous shedding of esophageal mucosa, and localized esophageal strictures in the absence of mucocutaneous lesions [2]. Although the presence of lymphoma was unlikely to be coincidental in this patient, we found no histological features to suggest that this was an unusual manifestation of paraneoplastic pemphigus. The patient's medical history suggests an autoimmune process [3], although there were no other features suggestive of this and corticosteroid treatment was ineffective. Rituximab has been used to treat pemphigus associated with lymphoproliferative disease $[4,5]$, and the rapid clinical and endoscopic response that this treatment brought about in our patient suggests that it can also be used to treat esophagitis dissecans.

Endoscopy_UCTN_Code_CCL_1AB_2AC_3AD Endoscopy_UCTN_Code_CCL_1AB_2AC_3AH

N. K. Patel ${ }^{1}$, C. Salathé ${ }^{2}$, C. Vu ${ }^{3}$,

S. H. C. .Anderson ${ }^{1}$

Department of Gastroenterology,

St. Thomas' Hospital, Guy's and

St. Thomas' NHS Trust, London, United Kingdom

2 Department of Internal Medicine, University Hospital Geneva, Geneva, Switzerland

3 Department of Gastroenterology, Tan Tock Seng Hospital, Singapore

\section{References}

1 Ponsot P, Molas G, Scoazec JY et al. Chronic esophagitis dissecans: an unrecognized clinicopathologic entity? Gastrointest Endosc 1997; 45: 38-45

2 Coppola D, Lu L, Boyce HW. Chronic esophagitis dissecans presenting with esophageal strictures: a case report. Hum Pathol 2000; 31: $1313-1317$

3 Varoczy L, Gergerly L, Zeher M et al. Malignant lymphoma-associated autoimmune diseases: a descriptive epidemiological study. Rheumatol Int 2002; 22: 233 - 237

4 Heizmann M, Itin P, Wernli M et al. Successful treatment of paraneoplastic pemphigus in follicular NHL with rituximab: report of a case and review of treatment of paraneoplastic pemphigus in NHL and CLL. Am J Haematol 2001; 66: 142 - 144

5 Rastetter W, Molina A, White CA. Rituximab: expanding role in therapy for lymphomas and auto-immune disease. Ann Rev Med 2004; 55: 477-503

\section{Bibliography}

Dol $10.1055 / \mathrm{s}-2007-966151$

Endoscopy 2007; 39: E127

(c) Georg Thieme Verlag KG Stuttgart · New York . ISSN 0013-726X

\section{Corresponding author}

\section{S. Anderson}

Department of Gastroenterology

St. Thomas' Hospital

Lambeth Palace Road

London SE1 7EH

United Kingdom

Fax: +44-207-188-4707

simon.anderson@gstt.nhs.uk 